\title{
Erratum to: First record of the invasive pest Drosophila suzukii in Ukraine indicates multiple sources of invasion
}

\author{
Anton Lavrinienko ${ }^{1,2}$ (iD $\cdot$ Jenni Kesäniemi ${ }^{1}$ Phillip C. Watts ${ }^{1} \cdot$ Svitlana Serga $^{2}$. \\ Marta Pascual $^{3}$ - Francesc Mestres ${ }^{3}$ - Iryna Kozeretska ${ }^{2}$
}

Published online: 19 December 2016

(c) Springer-Verlag Berlin Heidelberg 2016

\section{Erratum to: J Pest Sci \\ DOI 10.1007/s10340-016-0810-3}

Figure 2 has been published incorrectly in the online version of the original publication of the article, due to the error during the HTML image creation. The correct version of the Fig. 2 is provided here.

Figure 2 was corrected in the original article.

The online version of the original article can be found under doi:10.1007/s10340-016-0810-3.

Anton Lavrinienko

Anton.Lavrinienko@oulu.fi

1 Department of Ecology, University of Oulu, 90014 Oulu, Finland

2 Department of General and Molecular Genetics, ESC

"Institute of Biology", Taras Shevchenko National

University of Kyiv, Kyiv 01601, Ukraine

3 Departament de Genètica, Microbiologia i Estadística, IRBio, Universitat de Barcelona, 08028 Barcelona, Spain

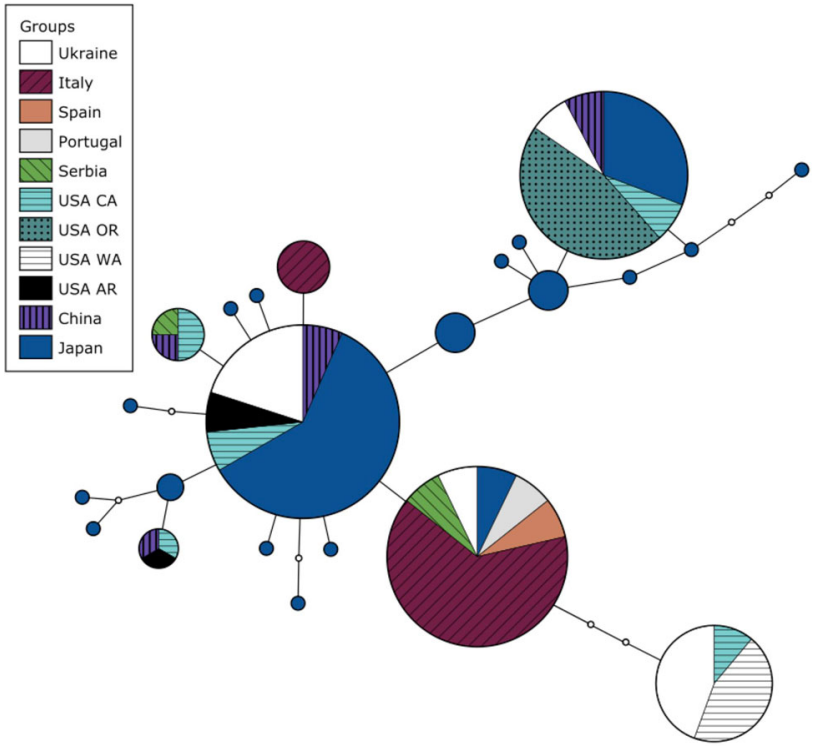

Fig. 2 Haplotype network of $C O I$ gene fragment (606 bp) for $D$. suzukii sampled from Ukraine, other European countries, USA, China and Japan. Small white circles represent undetected intermediate haplotypes, and each line corresponds to a mutational step. The area of the circles represents the amount of identical COI gene sequences in the alignment (Electronic Supplementary Material 1 and 2) 